\title{
Induced somatic sector analysis of cellulose synthase (CesA) promoter regions in woody stem tissues
}

${ }^{1}$ Nicky M. Creux, ${ }^{2 \S}$ Gerd Bossinger, ${ }^{1}$ Alexander A. Myburg, ${ }^{2}$ Antanas V. Spokevicius

${ }^{1}$ Department of Genetics, Forestry and Agricultural Biotechnology Institute (FABI),

University of Pretoria, Pretoria, 0002, South Africa

${ }^{2}$ Department of Forest and Ecosystem Science, Melbourne School of Land and Environment, The University of Melbourne, Creswick, Victoria, Australia

${ }^{\S}$ Corresponding author:

Gerd Bossinger

Department of Forest and Ecosystem Science

The University of Melbourne

Tel: +61353214176

Fax: +61353214135

Email: gerd@unimelb.edu.au 


\begin{abstract}
The increasing focus on plantation forestry as a renewable source of cellulosic biomass has emphasized the need for tools to study the unique biology of woody genera such as Eucalyptus, Populus and Pinus. The domestication of these woody crops is hampered by long generation times, and breeders are now looking to molecular approaches such as markerassisted breeding and genetic modification to accelerate tree improvement. Much of what is known about genes involved in the growth and development of plants has come from studies of herbaceous models such as Arabidopsis and rice. However, transferring this information to woody plants often proves difficult, especially for genes expressed in woody stems. Here we report the use of Induced Somatic Sector Analysis (ISSA) for characterization of promoter expression patterns directly in the stems of Populus and Eucalyptus trees. As a case study, we used previously characterized primary and secondary cell wall related cellulose synthase (CesA) promoters cloned from Eucalyptus grandis. We show that ISSA can be used to elucidate the phloem and xylem expression patterns of the CesA genes in Eucalyptus and Populus stems, and also show that the staining patterns differ in Eucalyptus and Populus stems. These findings show that ISSA is an efficient approach to investigate promoter function in the developmental context of woody plant tissues and raise questions about the suitability of heterologous promoters for genetic manipulation in plant species.
\end{abstract}

Keywords: CAMV35S promoter; Eucalyptus; GUS reporter gene; Populus; Secondary cell wall; Wood formation

Abbreviations ATS, Average of transformed sectors per $\mathrm{cm}^{2}$; ISSA, Induced Somatic Sector Analysis 


\section{Introduction}

Plantation tree species such as those from the genera Populus and Eucalyptus are receiving attention world-wide for their capacity to produce cellulosic biomass which can be used for pulp and, potentially, biofuel production (Hinchee et al. 2011). Unlike first generation biofuel crops such as sugarcane and maize, forest trees are less likely to directly compete with food production and have a greater biomass production capacity (Rathmann et al. 2010), although the processing of lignin-rich woody biomass to liberate cell wall biopolymers remains a challenge (Mansfield 2009). Furthermore, the genetic improvement of forest trees is hindered by long generation times and late expression of mature traits. Tree breeders attempting to enhance properties such as wood quality and cellulose deposition will benefit from the application of molecular approaches such as marker-assisted breeding (MAB) and genetic modification (Grattapaglia et al. 2009; Seguin 2011). These molecular approaches are now also benefiting from the application of next-generation genomics technologies, which can be used to study the genetics of wood formation as a system and to rapidly identify candidate genes for further functional analysis (Mizrachi et al. 2012).

Cellulose is deposited in plant cell walls by large, membrane bound, protein complexes composed of several different cellulose synthase (CESA) proteins (Kimura et al. 1999), the identity of which depends on the type of cell wall being laid down (Song et al. 2010). In Arabidopsis and other plant species, three CesA genes (CesA4, 7 and 8 ) have been associated with secondary cell wall deposition, while a different set of CesA genes were found to be involved in primary cell wall formation (Turner and Somerville 1997; Taylor et al. 2000, 2003; Hamann et al. 2004; Samuga and Joshi 2004; Ranik and Myburg 2006). During primary cell wall formation in Arabidopsis two CesA genes, AtCesAl and 3, are essential for cell development with knock-out mutants being lethal (Arioli et al. 1998; Scheible et al. 2001). Five other CesA genes (AtCesA2, 4, 5, 6 and 9) have been linked to 
primary cell wall formation in Arabidopsis, but these are functionally redundant when mutated, and appear to be involved in tissue-specific primary cell wall formation (Beeckman et al. 2002; Desprez et al. 2002; Stork et al. 2010; Carroll and Specht 2011).

While there are many similarities in cellulose biosynthesis across plant genera (Popper et al. 2011), there are also a number of species-specific features. The CesA gene family has ten members in Arabidopsis (Richmond and Somerville 2000), while Populus has 18 expressed CesA genes (Djerbi et al. 2005; Suzuki et al. 2006; Kumar et al. 2009). A phylogenetic analysis of the Populus CesA gene family revealed that the 18 CesA genes grouped with the ten Arabidopsis orthologs in all of the primary and secondary cell wall related clades and that Populus has two or more paralogs of some Arabidopsis genes (Kumar et al. 2009). In particular, it was noted that Populus has duplicated genes for the secondary cell wall associated AtCesA7 and AtCesA8 genes. In each case, one of the two Populus paralogs (PtiCesA7-A or PtiCesA8-B) was more highly expressed in xylem, suggesting differential regulation of the paralogs and possible loss of regulation of the lower expressed paralog (Suzuki et al. 2006). Similarly, the primary cell wall associated AtCesA3 gene has four close orthologs in Populus, and each of these have a different expression pattern (Suzuki et al. 2006). The differentiated expression patterns of the duplicated CesA genes in Populus suggest that the Populus paralogs may be undergoing subfunctionalization.

Inter-specific differentiation can affect regulatory sequences in promoters and produce discordant results when different orthologs are used in transgene constructs. Fei et al. (2006) found that a promoter construct which increased glutamine synthase expression in both Lotus japonicus and Sesbania rostrata, did not produce a corresponding increase in expression in Pisum sativum. In an extensive study on mammalian and Drosophila cell lines eight supposedly constitutive promoters were tested and most promoters showed variation in reporter gene expression between both cell line and species (Qin et al. 2010). Even the highly 
utilized CAMV 35S promoter has been shown to have differential expression across different species (Benfey and Chua 1990; Zhang et al. 2003). This evidence suggests that for some promoters it may be desirable to perform functional analysis in the native genetic backgrounds, however, this may not be practical in species that are recalcitrant to genetic transformation.

Induced Somatic Sector Analysis (ISSA), first proposed by Spokevicius et al. (2005) and developed further by Van Beveren et al. (2006), uses a novel in planta transformation method, which has been successfully applied in the analysis of transgenes in woody stem tissues of Pinus, Populus and Eucalyptus (Hussey et al. 2011). In this method, Agrobacterium carrying the promoter and transgene of interest is applied to the exposed cambium on the stem of a living tree. The gene construct is transferred by Agrobacterium into actively dividing cambial, xylem, phloem and ray initial cells, creating a number of transformants in this small section $\left(\sim 1 \mathrm{~cm}^{2}\right)$ of the tree stem (Van Beveren et al. 2006). When the cambium is resealed and the stem is allowed to grow for a few months where the transformed cells divide and multiply within the stem, producing somatic sectors of transformed cells. This area of transformed cells can then be analyzed for transgene (e.g. $\beta$-glucuronidase) expression and changes in cell wall morphology by comparing transformed sectors to adjacent nontransformed stem cells. ISSA has great potential for functional genetic studies, as it allows for the analysis of transgenes and promoters directly in the stem tissues of the tree and, for woodspecific constructs, may give a more accurate picture of the native functions or expression patterns of transgenes in woody tissues (Spokevicius et al. 2007).

Here, we used ISSA to study the expression patterns of six previously characterized promoters of Eucalyptus grandis CesA genes (Creux et al. 2008) in woody stem tissues of Eucalyptus and Populus trees. The first objective of this study was to investigate the suitability of ISSA for the analysis of promoter function in various woody stem tissues. 
Secondly, we assessed whether ISSA could be used to compare reporter gene expression patterns in Populus and Eucalyptus stems. To our knowledge, this is the first study to directly compare the expression patterns of promoter::reporter gene constructs in woody tissues of Populus, the model tree genus for molecular studies, and Eucalyptus, a globally important fibre crop.

\section{Materials and methods}

Plant material

Three-month-old ramets of five Eucalyptus camaldulensis $x$ globulus and six Eucalyptus camaldulensis x grandis clones were purchased from a specialist forestry nursery (Narromine Transplants, Narromine, NSW, Australia), potted in premium potting mix and maintained in a greenhouse for another four months. A single Populus alba (L.) 'pyramidalis' clone, growing at the University of Melbourne Creswick Campus (Vic. Australia), was used to generate plant material through rooted cuttings. Dormant stems were sourced and established in cutting beds following treatment with a commercial rooting hormone powder (Yates Striking Powder, Homebush, NSW), transplanted into premium potting mix after six weeks and maintained in the greenhouse for three months until required. Greenhouse temperatures were maintained between $14^{\circ} \mathrm{C}$ and $17^{\circ} \mathrm{C}$ at night and between $21^{\circ} \mathrm{C}$ and $25^{\circ} \mathrm{C}$ during the day. A 16-hour photoperiod was kept through supplementary lighting. Supplementary lighting was supplied by six $1000 \mathrm{~W}$ Metal Halide globes in a glasshouse chamber of approximately $16 \mathrm{~m}^{2}$. All plants were watered regularly with tap water (as required, depending on season) and fertilised with a slow release formulation (Osmocote Exact Mini, Scotts-Sierra Horticultural Products, Marysville, OH, USA) every three months. 
Promoter isolation, vector and Agrobacterium preparation

Kumar et al. (2009) proposed a revision of the CesA gene nomenclature for the Populus CesA genes, which allows for the direct comparison of the Arabidopsis and Populus CesA genes (See Table 1 for CesA gene orthology). The change in nomenclature has not yet been applied to the Eucalyptus CesAs and for this reason we have retained the naming convention first published by Ranik and Myburg (2006). The Eucalyptus CesA promoter regions (EgCesA1-5 and 7) and the Arabidopsis CesA8 promoter region were cloned into the pCR8/GW/TOPO entry vector (Invitrogen). Orientation of the inserts was determined using restriction endonuclease digestion. Promoter DNA was transferred from the entry vectors to the binary vector pMDC162 (Curtis and Grossniklaus 2003) using LR Clonase (Invitrogen) according to the manufacturer's instructions. The expression cassette consisting of the promoter and GUS ( $\beta$-glucuronidase) reporter gene was confirmed by sequencing prior to Agrobacterium transformation (Creux et al. 2008).

Two CAMV 35S promoter vectors were used as a positive control. The first, 35S-F, was the pCAMBIA1305.1 vector (http://www.cambia.org/ verified 5/5/10) and the second, 35S-G, was based on the same pCAMBIA1305.1 vector backbone, but with a Gateway recombinase cassette in the multi-cloning region. An empty (promoter-less) pMDC162 vector was also used as negative control.

All vectors were transformed into AGL-1, a disarmed strain of Agrobacterium tumefaciens containing a derivative of pTiBO542 (Lazo et al. 1991), using an E. coli pulsar (BIO-RAD Laboratories, Gladesville, NSW, Australia), $2 \mathrm{~mm}$ cuvette and $2.5 \mathrm{kV}$, and following protocol 26 'transformation of E. coli by electroporation' as described in Sambrook and Russell (2001). Bacteria were grown for $48 \mathrm{~h}$ at $28^{\circ} \mathrm{C}$ in $\mathrm{LB}$ medium containing $25 \mu \mathrm{g}$ $\mathrm{mL}^{\subseteq 1}$ rifampicin and $50 \mu \mathrm{g} \mathrm{mL} \mathrm{m}^{\subseteq 1}$ kanamycin. The Agrobacterium suspension was then diluted 
1:20 with fresh $\mathrm{LB}$ and grown to $\mathrm{OD}_{600}$ of 0.4 to 0.6 after which the cells were recovered by centrifugation (1150 $\mathrm{g}$ for $15 \mathrm{~min}$ ) and resuspended in $1 \mathrm{~mL}$ of Murashige-Skoog (MS) media prior to inoculation (Table 2).

Inoculation and harvest of transformed tissues for Induced Somatic Sector Analysis

During the start of the growing season (early summer) 40 P. alba 'pyramidalis', 20 E. camaldulensis $x$ globulus (four ramets of each clone) and 24 E. camaldulensis $x$ grandis (four ramets of each clone) potted plants were selected on the basis of good form and growth for experimentation (Table 2). Along the stem of each tree, eleven approximately $1 \mathrm{~cm}^{2}$ cambial windows were opened using the in vivo stem ISSA method described in Van Beveren et al. (2006). Each cambial window was inoculated with $5 \mu \mathrm{L}$ of Agrobacterium suspension containing one of the 11 promoter constructs under investigation (one promoter per window) and subsequently sealed using parafilm. Due to lower sector numbers for the EgCesAl and EgCesA2 promoters (see Results) a further 30 windows were produced for each promoter in both species (Eucalyptus and Populus) during the following year using the same clonal material. Plant height and stem diameter (measured at a height of $10 \mathrm{~cm}$ from the trunk base) were recorded. Plants were fertilised after inoculation and maintained in the greenhouse until harvest.

At harvest, plant height and stem diameter (measured at a height of $10 \mathrm{~cm}$ from the trunk base) were again recorded and stem sections harbouring cambial windows were excised from the main stem and placed in $10 \mathrm{ml}$ Falcon tubes for transport. Un-inoculated stem tissue (outside the window area) was removed and the remaining cambial tissue was cut transversely into $1 \mathrm{~mm}$ half-discs and placed back into the $10 \mathrm{~mL}$ tubes for GUS assays. Cambial discs were washed twice with $0.1 \mathrm{M} \mathrm{NaPO}_{4}$ buffer $(\mathrm{pH}$ 7) prior to the addition of 5 $\mathrm{mL}$ (approx) of GUS solution ( $0.1 \mathrm{M} \mathrm{NaPO}_{4}$ buffer $\mathrm{pH} 7,0.5 \%$ v/v Triton X-100 (Sigma), 10 
mM EDTA (Sigma), $0.5 \mathrm{mM}$ potassium ferricyanide (III) (Sigma), $0.5 \mathrm{mM}$ potassium hexacyanoferrate (II) trihydrate (Sigma), $0.5 \mathrm{mM} \mathrm{X-Gluc).} \mathrm{Cambial} \mathrm{discs} \mathrm{were} \mathrm{incubated} \mathrm{in}$ a water bath in GUS solution at $55^{\circ} \mathrm{C}$ for $10 \mathrm{~min}$ prior to being placed upright in the dark on a rotary shaker $(150 \mathrm{rpm})$ at $37^{\circ} \mathrm{C}$ overnight. The GUS solution was then replaced with $70 \%$ ethanol and samples were stored at $4{ }^{\circ} \mathrm{C}$ until assessment (Spokevicius et al 2005; Alwen et al 1992).

Assessment of GUS staining patterns

For the purpose of promoter expression analysis, it is important to note that the observed "sector types" described in this study in all cases represent the net staining pattern produced by the combined effect of the initial cell transformed (determining the total sector of transformed cells) and the cell/tissue specificity of the promoter construct tested (specifying the subpopulation of cells within the sector that express GUS). Cambial windows were initially assessed for GUS staining using protocols described in previous ISSA studies where whole sectors were investigated (Spokevicius et al. 2006; Van Beveren et al. 2006). In most cases, the sector was transversely cut into two and each half was examined under a microscope. Generally, correct identification of sector type and staining pattern could be made without any further examination due to a combination of the intensity of the GUS staining, the transparency of the wood, sector size and the experience of investigators. Where identification was not certain upon initial investigation, serial sectioning was undertaken on the two halves until correct identification could be made. The sector categories described in the previous studies (Spokevicius et al. 2006; Van Beveren et al. 2006) were also used in this study in addition to new sector categories. The same 'tylose' and 'wound parenchyma' sector categories were used as before, but 'cambial' and 'phloem' sectors were redefined to include the addition of two new sector pattern types, indicative of the cell type that was initially 
transformed and the subsequent expression pattern of the promoter tested. In the case of 'cambial' sectors, these were reclassified into two subcategories. The first subcategory, 'xylem mother sectors' (Fig. 1a), was characterized by GUS staining in the newly derived xylem cells extending for a short distance from the wound parenchyma. 'Xylem mother sectors' are indicative of the initial transformation of a xylem mother cell and the formation of a transgenic xylem sector which terminates after a number of cell divisions when the xylem mother cell is replaced by an adjacent, non-transgenic mother cell, or when it terminally differentiates and therefore ceases to be a mother cell. A second subcategory was defined as 'cambial sector proper' (Fig. 1a), where GUS staining was observed in and around the cambial region, which indicates that an undifferentiated cambial initial was transformed which continued to produce xylem and phloem mother cells and sectors of xylem and phloem cells derived from these mother cells. The definition of a 'cambial sector proper' had to be expanded for the promoter analysis because the tissue specificity of the promoters investigated could produce GUS staining patterns that differ from the original sector descriptions which were based on constitutive GUS expression (Fig. 1a - original descriptions and Fig. 1c - new cambial staining patterns). While a "cambial sector proper" may produce transgenic xylem and phloem sectors, GUS staining would only be seen in the xylem for example if a xylem-specific promoter was tested. During this stage of assessment, the amount of new growth (wound parenchyma and xylem tissue) was measured in millimetres using a dissecting microscope to give an indication of the extent of growth that occurred post inoculation.

Cambial sectors were further analyzed to gain insight into the temporal and spatial activity of the promoters under investigation, referred to here as 'cambial sector ratio'. For this analysis, cambial sectors were assessed for presence or absence of GUS staining in three distinct regions defined as $\mathrm{X} 1, \mathrm{X} 2$, and $\mathrm{P}$ (Fig. 1b). The $\mathrm{X} 2$ region extended outward from the 
initial wound parenchyma cells up to the end of the mature xylem. Staining observed in this region was indicative of promoter activity in ray cells which extend radially through the stem. Most xylem fibres and vessels in the $\mathrm{X} 2$ region have already undergone programmed cell death (PCD) and one would therefore only expect X2 GUS expression and staining in ray cells which have not undergone $\mathrm{PCD}$. The $\mathrm{X} 1$ region was characterized by staining in developing xylem cells close to and including the cambial zone (but no staining on the phloem side). Staining observed in the $\mathrm{X} 1$ region was indicative of promoter activity in differentiating xylem cells (before the onset of $\mathrm{PCD}$ ). The $\mathrm{P}$ region comprised all phloem tissues and GUS staining in this region was indicative of promoter activity in phloem tissue in general. It is important to again note here that the final staining pattern observed (combination of $\mathrm{P}, \mathrm{X} 1$ and $\mathrm{X} 2$ ) was determined by the cell type initially transformed and the specificity of the promoter tested.

Statistical analysis of ISSA results

Details of the statistical analysis are outlined in the Results section. Confidence intervals (95\%) were calculated for growth data using Minitab (Minitab Inc., State College, PA, USA) to compare growth rates. Chi-squared tests were performed using Minitab to compare the frequency of GUS expressing sectors observed in the X1, X2 and P regions (at $\alpha=0.05$ ). Promoter constructs for which fewer than 10 sectors were observed were excluded from the statistical analysis, as was the case for the EgCesA2 and EgCesA4 in Populus stems. However, the majority of sectors observed for these promoters were cambial sectors and data for these promoters were included in the graphs, but should be validated in future experiments. 


\section{Results}

The number of transformed sectors varied dependent on species and promoter

In total, inoculated stem tissue with a surface area of $559 \mathrm{~cm}^{2}$ (Eucalyptus: $258 \mathrm{~cm}^{2}$ and Populus: $240 \mathrm{~cm}^{2}$ ) was harvested and stained for GUS activity, with 2558 transformed tissue sectors identified for the 10 promoter constructs investigated (Table 2). Overall, more GUS expressing sectors were identified in Eucalyptus stem tissues with a total of 1661 and an average of 6.4 transformed sectors per $\mathrm{cm}^{2}$ of inoculated tissue $\left(\mathrm{ATS}^{-2}\right.$ ). In Populus stems only 897 sectors were counted, with an $\mathrm{ATS}^{-2}$ of 3.7 (Table 2). In the Populus and Eucalyptus stems, the $35 S:$ GUS ( $\mathrm{F}$ and $\mathrm{G}$ ) constructs resulted in the highest $\mathrm{ATS}^{-2}$ values ranging from 12.0 to 27.1 (Table 3), which is a measure of overall transformation efficiency as the $35 \mathrm{~S}$ promoters are expressed ubiquitously in most plants. No sectors were observed in windows inoculated with the promoter-less pMDC162 vector (negative control). The highest $\mathrm{ATS}^{-2}$ value for the CesA promoters was observed for the AtCesA8 promoter construct in Eucalyptus $\left(\mathrm{ATS}^{-2}=9.4\right)$ and Populus stems $\left(\mathrm{ATS}^{-2}=5.2\right)$, while the lowest values were observed for

the EgCesA2 promoter with an $\mathrm{ATS}^{-2}$ value of 0.6 for Eucalyptus and $\mathrm{ATS}^{-2}$ of 0.3 in Populus stems (Table 3). It is important to note that the $\mathrm{ATS}^{-2}$ values for the CesA promoters are more likely to reflect the spatio-temporal regulation of these promoters and the lower values are likely due to the smaller subset of tissues in which the promoters are active.

Sector type and frequency differed between promoter constructs

Overall, the most abundant sector types observed were phloem, xylem mother and cambial sectors, while periderm sectors only occurred at very low frequencies in Populus and Eucalyptus stems (Fig. 2a and b). As expected, the constitutive $35 \mathrm{~S}$ promoter constructs (F and $\mathrm{G}$ ) produced a wider range of sector types than the CesA promoter constructs (Fig. 2a and 
b). All of the major sector types were represented in Populus stems inoculated with the two $35 \mathrm{~S}$ constructs, including periderm and tylose sectors, which are induced upon wounding (Van Beveren et al. 2006). In Eucalyptus stems, no periderm or tylose sectors were recorded for the $35 \mathrm{~S}$ constructs, and the ratio of sector types observed for the $35 \mathrm{~S}$ constructs was distinctly different to that of the CesA promoter constructs (Fig. 2b). In both species, the CesA promoter constructs produced a high frequency of cambial and xylem mother sectors (Fig. 2a and b). In Populus stems, the CesA promoter constructs also produced phloem sector types at high frequencies (15\% to 40\%) in five (EgCesA3, 4, 5, 7 and AtCesA8) of the seven CesA promoter constructs investigated (Fig. 2a). This included the secondary cell wall related CesA promoters ( $E g \operatorname{Ces} A 3$ and $A t C e s A 8)$ for which low numbers of phloem sectors were observed in Eucalyptus stems (Fig. 2b).

Cambial sectors were the most abundant and varied among species and promoter constructs

Cambial sectors were highly abundant in Populus and Eucalyptus stems (Fig. 2a and b) and these sectors were further classified into expression patterns (Fig. 2c and d). Five different cambial expression patterns were observed in the two species which included $\mathrm{X} 2+\mathrm{X} 1+\mathrm{P}$, $\mathrm{X} 2+\mathrm{X} 1, \mathrm{X} 1+\mathrm{P}, \mathrm{X} 1$-only and $\mathrm{P}$-only ( Fig. 1b). The $\mathrm{X} 2+\mathrm{X} 1+\mathrm{P}$ sector type was most likely produced by the transformation of a cambial initial, which subsequently gave rise to a ray sector extending into the $\mathrm{P}, \mathrm{X} 1$ and $\mathrm{X} 2$ region followed by promoter activity in all three regions (Fig. 1c). The $\mathrm{X} 2+\mathrm{X} 1$ sector type could be the result of transformation of a ray initial on the xylem side, or xylem-specific promoter activity in a cambial sector giving rise to ray cells. The $\mathrm{X} 1+\mathrm{P}$ sector type was most likely the result of transformation of a cambial initial differentiating into phloem $(\mathrm{P})$ and xylem $(\mathrm{X} 1)$, but terminating at the zone of PCD (X1/X2 border), and subsequent promoter activity in phloem and xylem cells. X1-only and P-only sectors could be produced by the transformation of a cambial initial followed by xylem or 
phloem promoter activity, or the transformation of a xylem or phloem mother cell, respectively, followed by promoter activity in the resulting xylem or phloem sector. No X2only or $\mathrm{X} 2+\mathrm{P}$ staining patterns were detected in either species.

In the case of the two $35 S$ promoter constructs ( $F$ and $\mathrm{G}$ ) all cambial sector types (Fig. 1b) were found in Eucalyptus stems (Fig. 2d), but three (X2+X1+P, X1+P and P-only) accounted for the majority of cambial staining patterns observed in Populus stems (Fig. 2c). In both species, the $\mathrm{X} 2+\mathrm{X} 1+\mathrm{P}$ sector type was the highest frequency cambial staining pattern observed for the $35 \mathrm{~S}$ promoter constructs (approx $40 \%$ in Eucalyptus and 65\% in Populus stems). For the CesA promoter constructs, all cambial staining patterns (Fig. 1b) were identified, but with distinct differences in the frequencies of staining patterns between Populus and Eucalyptus stems.

In Eucalyptus stems, cambial sector X1-only was the most frequent type observed for

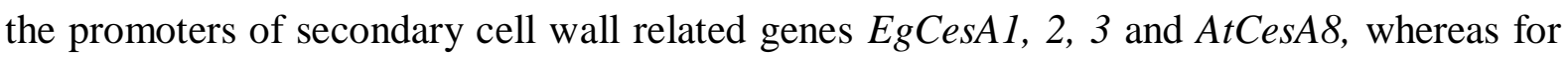
the promoters of the primary cell wall related genes $\operatorname{EgCesA} 4,5$ and 7 much higher frequencies of the $\mathrm{X} 1+\mathrm{P}$ cambial sector types in addition to X1-only were observed (Fig. $2 \mathrm{~d}$ ). In Populus stems, the secondary cell wall related CesA promoters also showed a high frequency of X1-only staining patterns, however, in Populus these promoters also displayed a higher frequency of the $\mathrm{X} 1+\mathrm{P}$ type sectors. The primary cell wall related CesA promoters produced a high proportion of $\mathrm{X} 1+\mathrm{P}$ sectors in the Populus stems, similar to the pattern observed in Eucalyptus, but there was also a number of $\mathrm{X} 2+\mathrm{X} 1+\mathrm{P}$ and $\mathrm{P}$ only sectors present (Fig. 2c).

Some CesA promoters showed similar activity to the $35 S$ promoter

We next investigated whether any of the CesA promoter constructs exhibited similar or different cambial sector (staining pattern) ratios when compared to the $35 \mathrm{~S}$ promoter 
constructs (Chi-squared tests, Table 4). Cambial sector ratios were derived from the spatial temporal data sourced from cambial sectors (ratio of X2, X1, P). In Eucalyptus stems, all of the CesA promoter constructs exhibited significantly different $(\alpha=0.05)$ cambial sector ratios from that of the $35 S$ promoter constructs (Fig. $3 \mathrm{~b}$ and Table 4). In Populus stems, the cambial sector ratios of some CesA promoters, such as EgCesA4 and 5, were not significantly different from that of the $35 \mathrm{~S}$ promoter constructs (Table 4) and in general the expression pattern seemed to be more variable than in Eucalyptus (Fig. 2c). This result suggests that there is a difference in Populus and Eucalyptus stems, either on a developmental or anatomical level as a result of different cell/tissue patterning, and/or on a genetic level with different transcriptional regulation of the CesA promoters.

Patterns of individual CesA promoter activity between tree species

We directly compared the cambial staining patterns observed for each promoter construct between the two species. We found that the $35 \mathrm{~S}$ promoter staining patterns were not significantly different in Populus and Eucalyptus tissues irrespective of the vector backbone (Table 5). This confirmed that the Populus and Eucalyptus stem tissues did not have significantly different relative transformation efficiencies in cells giving rise to $\mathrm{X} 1, \mathrm{X} 2$ and $\mathrm{P}$ staining patterns, although the Populus stems exhibited lower overall transformation efficiency (Table 3). The similarity of the staining patterns observed for the $35 \mathrm{~S}$ promoter in Eucalyptus and Populus stems also suggests that differences in the amount of diffusion of GUS observed in the Populus and Eucalyptus stems did not greatly influence the resulting sector frequencies. In contrast, all the CesA promoter constructs (except the EgCesA5 promoter), exhibited statistically significant differences $(\alpha=0.05)$ in cambial sector ratios between Eucalyptus and Populus stems (Table 5). Differences in EgCesA1, 2 and 3 and 
AtCesA 8 promoter activity could be attributed to activity being confined mostly to the $\mathrm{X} 1$ (developing xylem) region of Eucalyptus (Fig. 3b and Fig. 4a,b), whereas in Populus stems, activity was observed at similar frequencies in both the X1 and P regions (Fig. 3c and Fig. 4e,f). In the case of the EgCesA4 and 7 promoters, the majority of activity was observed in the X1 and P regions in Eucalyptus (Fig. 3b), while in Populus stems a higher proportion of observations were in the $\mathrm{P}$ and $\mathrm{X} 2$ (mature xylem) regions (Fig. 3a).

\section{Discussion}

ISSA provides a rapid and efficient approach to evaluate promoter expression in woody stems

Gene and promoter testing in tree genera such as Eucalyptus, Populus or Pinus require timeconsuming and laborious manipulation through tissue culture and greenhouse studies. In this study we investigated the use of Induced Somatic Sector Analysis (ISSA, Spokevicius et al. 2005; Van Beveren et al. 2006) as an approach for rapid functional genetic analysis of promoter expression patterns in developing woody tissues based on large numbers of independent transgenic events. We demonstrate the suitability of ISSA for promoter expression analysis of six Eucalyptus cellulose synthase (CesA) genes in the stems of Eucalyptus and Populus trees. We show that in the Eucalyptus genetic background the EgCesA promoters produced distinct staining patterns, which were consistent with the primary and secondary cell wall associated expression patterns previously demonstrated for these genes (Samuga and Joshi 2004; Ranik and Myburg 2006), whereas in the heterologous Populus genetic background the staining patterns of the two groups of Eucalyptus CesA genes were less distinct. 
There are a number of key advantages to using ISSA for functional genetic analysis of wood formation genes and promoters. First, it allows the testing of transgenic constructs directly in native woody tissues (e.g. Pinus, Populus and Eucalyptus) in a relatively short period of time yielding measurable results within a few months (Spokevicius et al. 2005). Second, this technique requires little greenhouse space because multiple constructs or replicate transformations (up to 10 windows) can be performed on a single tree stem. Finally, a major advantage of ISSA is that each transgenic sector represents an independent transformation event, and with ten inoculation windows per tree a large number of independent events are produced, which can then be statistically analysed. For these reasons ISSA can be a useful technique to quickly screen promoter constructs for expression in woody stem tissue, in order to select candidate promoters for more detailed whole-plant analyses in model species such as Arabidopsis or Populus.

An important aspect to consider when analysing ISSA data is that stem tissue is comprised of different cell types at different developmental stages (Plomion et al. 2001) each of which may respond differently to transformation by Agrobacterium. Similarly, genetic background and species-specific developmental patterns may affect transformation efficiency. For example the periderm sectors, which are a result of transformed cells near the cut surface of the cambial window and have undergone rounds of division during the wounding response, were observed for most of the promoter constructs transformed into Populus stems. No such sectors were observed in Eucalyptus stems (Fig. 2) suggesting that this tissue is recalcitrant to transformation or responds differently to wounding in Eucalyptus. Another important consideration for analysing promoter regions using ISSA is the cell fate of the initially transformed cell and the cell- or tissue-specificity of the promoter construct. These two factors determine the final staining pattern observed and have to be jointly considered in the analysis of tissue- or cell type- specific promoters. We found it useful to 
compare the sector type frequencies obtained for the CesA promoters to those obtained for the CAMV35S promoter constructs (Fig. 3), which for the purpose of this study we assumed to be constitutively expressed in all cells derived from transformed initials. The latter is supported by the observation of a more diverse set of sector types for the CAMV35S promoter constructs including a higher frequency of wound parenchyma and tylose sectors (Fig. 2a and b), suggesting that these tissues are indeed susceptible to transformation, but that tissue-specific regulation resulted in low sector counts for these tissues when transformed with the $\operatorname{Ces} A$ promoter constructs.

The CAMV35S control promoter was expressed in all stem tissues and exhibited similar cambial expression patterns in Eucalyptus and Populus stems

One of the aims of this study was to investigate the suitability of ISSA for assessing and comparing promoter activity in woody stems across plant species and genera. Towards this end, we first asked whether the observed sector types and staining patterns were indeed comparable among species, because it has been noted before that even constitutive promoters such as CAMV35S can show variable expression across species (Qin et al. 2010). Similar to previous results (Van Beveren et al. 2006) we found that the CAMV35S promoter was active in most sampled stem tissue types (Fig. 2a,b) and this was to be expected as the CAMV35S promoter is constitutive and will express GUS in most plant tissues (Odell et al. 1985; Jefferson et al. 1987; Benfey and Chua 1990). The comparison of CAMV35S driven GUS expression patterns in cambial derived sectors observed in Eucalyptus and Populus stems did not show any significant differences (Table 5), however, other sector types such as the tylose sectors exhibited very different frequencies presumably due to differences in the susceptibility of cell types to transformation (Fig. 2a and b). Together these results suggest 
that ISSA can be used to compare promoter expression patterns across species using either sector type (Fig. 2) or cambial staining patterns (Fig. 3), provided that the inherent differences in transformation efficiency are accounted for by using a standard constitutive promoter construct such as CAMV35S.

Staining patterns for CesA promoters in cambial derived tissues showed clear grouping of primary and secondary cell wall related promoters

In a previous study, the expression patterns of the Arabidopsis (AtCesA8) and Eucalyptus $($ EgCesA1) promoters were analyzed using promoter::GUS assays in Arabidopsis plants (Creux et al. 2008). This confirmed the secondary cell wall related expression patterns of these two functional orthologs (Ranik and Myburg 2006). We included the same two promoter constructs in this study to allow comparison of the ISSA results to that obtained by whole-plant transformation in Arabidopsis. We found that the cambial staining patterns obtained in Eucalyptus stems for these two promoter constructs, as well as for the other CesA genes (Fig. 3) were consistent with the expression patterns previously observed for these genes (Taylor et al. 2003; Taylor 2008; Ko et al. 2012). The EgCesA1, 2, 3 and AtCesA8 promoters produced GUS staining mostly in developing xylem cells (X1) which actively deposit secondary cell walls before the onset of PCD (Plomion et al. 2001) and are thus expected to show high $E g C e s A 1,2$ and 3 expression levels. Their distinct expression patterns may explain the lower net $\mathrm{ATS}^{-2}$ values $\left(\mathrm{ATS}^{-2}=0.7\right.$ for $E g C e s A 1$ to $\mathrm{ATS}^{-2}=2.0$ for EgCesA3) observed for the secondary cell wall associated Eucalyptus CesA promoters (Table 3). In contrast, higher $\mathrm{ATS}^{-2}$ values were observed for the primary cell wall related promoters (EgCesA4, 5 and 7), which reflected their expression in a wider range of cell types such as phloem (P), developing xylem (X1) and ray cells in mature xylem (X2) tissues. These results 
demonstrate that the ISSA approach was able to discriminate the distinct expression patterns of the Eucalyptus CesA genes in woody stem tissues.

The staining patterns of the CesA promoter constructs were not as distinctive in Populus stems as was observed for the primary and secondary cell wall associated CesA genes in Eucalyptus stems (Fig. 2c,d and Fig. 3a). In particular, the three secondary cell wall related Eucalyptus CesA promoters (EgCesA1, 2 and 3) did not predominantly produce developing xylem (X1) expression in Populus stems, but were expressed at equal frequency in phloem (P) and developing xylem (X1) tissues. This could be the result of differences between the regulatory networks of the two genera and has been reported in a number of other plant promoter studies (Zhang et al. 2003; Fei et al. 2006; Qin et al. 2010). While the transcriptional network regulating secondary cell wall deposition is thought to be largely conserved across plant species and genera (Zhong et al. 2010), there may be important differences in promoter sequence and transcription factor binding sites of these species. In well-studied models such as humans, fruit flies and yeast, cis-regulatory variation has been shown to be relatively common (Ho et al. 2009; Dowell 2010; Mu et al. 2011) and could underlie differences in reporter gene expression observed for the same promoter construct in different species, as was found in this study. Cis-element evolution within promoter sequences can give rise to subfunctionalization of duplicated gene loci in organisms such as Populus, which have undergone genome-wide or segmental duplications (Tuskan et al. 2006). Furthermore, the NAC domain transcription factor family harboring many of the key transcription factors involved in secondary cell wall formation is highly expanded in some plant genomes and the duplicated genes may be under different evolutionary pressures $(\mathrm{Hu}$ et al. 2010). These differences may explain the variation observed in reporter gene expression from different genetic backgrounds. Other possible sources of variation in the reporter gene 
expression observed for these two species could be on an anatomical or development level, but would require further investigation to elucidate this complex issue.

\section{Conclusion}

In this study we show that ISSA is an efficient approach to investigate promoter expression in the stems of woody plants such as Populus and Eucalyptus. ISSA requires less time and space to test promoters in woody stems than whole-plant transformation and regeneration, and provides ample independent transformation events for statistical analysis. However, it is important to include appropriate controls to interpret the ISSA staining patterns produced by transforming multiple cell types and using promoters with cell type- or developmental stagespecific expression. We found that the CesA promoter constructs produced distinct staining patterns in woody stem tissues consistent with the predicted roles of the corresponding CesA genes in primary and secondary cell wall formation. Our results suggest that, while many aspects of the secondary cell wall transcriptional network are conserved (Zhong et al. 2010), there are regulatory differences which should be considered when testing promoters in heterologous systems. ISSA should be applicable to a wider range of woody plants and various secondary cell wall related promoters could be analyzed in this manner, which will be important for elucidating the transcriptional control of woody biomass production.

\section{Acknowledgements}

We are grateful to Martin Ranik for providing the CesA-promoter::GUS constructs which made this study possible and Minique De Castro for aiding in the construction of the second CAMV35S-promoter::GUS construct. We also thank Julio Najera, Valerie Frassiant and Angelique Manuel for laboratory assistance. This work was supported through funding 
provided by Mondi and Sappi to the Forest Molecular Genetics (FMG) Programme, the Technology and Human Resources for Industry Programme (THRIP) and the National Research Foundation (NRF) of South Africa as well as a Linkage Grant from the Australian Research Council (LP0776563) to GB, AAM and AVS. 
Tables

Table 1 Arabidopsis thaliana and Populus trichocarpa CesA orthologs and the corresponding Eucalyptus grandis CesA genes included in this study

\begin{tabular}{cccc}
\hline & Arabidopsis $^{\mathrm{a}}$ & Eucalyptus $^{\mathrm{b}}$ & Populus $^{\mathrm{c}}$ \\
\hline Primary cell wall & AtCesA1 & EgCesA5 & PtiCesA1-A \\
associated CesA genes & AtCesA2 & EgCesA7 & PtiCesA6-A \\
& AtCesA3 & EgCesA4 & PtiCesA3-D \\
\hline Secondary cell wall & AtCesA4 & EgCesA2 & PtiCesA4 \\
associated CesA genes & AtCesA7 & EgCesA3 & PtiCesA7-A \\
& AtCesA8 & EgCesA1 & PtiCesA8-A \\
\hline
\end{tabular}

${ }^{a}$ All Arabidopsis ortholog information was obtained from TAIR (www.arabidopsis.org)

${ }^{\mathrm{b}}$ All Eucalyptus ortholog information was obtained from Phytozome (www.phytozome.org) and nomenclature for the EgCesA genes taken from previous publications (Ranik and Myburg 2006; Yin et al. 2009)

${ }^{c}$ All Populus ortholog information was obtained from Kumar et al. (2009) in which the Populus and Arabidopsis naming conventions were unified 
Table 2 Growth parameters and overall transformation efficiency for Eucalyptus and Populus plants

\begin{tabular}{lcc}
\hline Growth Parameters & Populus & Eucalyptus \\
\hline Average height at inoculation & $91.7 \mathrm{~cm}(\mathrm{SE}=5.0 \mathrm{~cm})$ & $168.9 \mathrm{~cm}(\mathrm{SE}=6.7 \mathrm{~cm})$ \\
Average height at harvest & $205.8 \mathrm{~cm}(\mathrm{SE}=6.9 \mathrm{~cm})$ & $247.7 \mathrm{~cm}(\mathrm{SE}=9.186 \mathrm{~cm})$ \\
$\begin{array}{l}\text { Average diameter at inoculation } \\
\text { (at stem height }=10 \mathrm{~cm})\end{array}$ & $6.2 \mathrm{~mm}(\mathrm{SE}=0.09 \mathrm{~mm})$ & $7.5 \mathrm{~mm}(\mathrm{SE}=0.17 \mathrm{~mm})$ \\
$\begin{array}{l}\text { Average diameter at harvest }(\text { at } \\
\text { stem height }=10 \mathrm{~cm})\end{array}$ & $11.4 \mathrm{~mm}(\mathrm{SE}=0.22 \mathrm{~mm})$ & $11.2 \mathrm{~mm}(\mathrm{SE}=0.33 \mathrm{~mm})$ \\
$\begin{array}{l}\text { Average total radial growth of } \\
\text { cambial window xylogenic tissue } \\
\text { (from wound site })\end{array}$ & $2.55 \mathrm{~mm}(\mathrm{SE}=0.03 \mathrm{~mm})$ & $1.67 \mathrm{~mm}(\mathrm{SE}=0.069 \mathrm{~mm})$ \\
Average total radial expansion rate & $0.022 \mathrm{~mm} / \mathrm{day}(\mathrm{SE}=0.001$ & $0.013 \mathrm{~mm} / \mathrm{day}(\mathrm{SE}=0.001$ \\
& mm/day $)$ & 1661 \\
Total number of sectors counted & 897 & 6.4 \\
${ }^{\text {aATS }}{ }^{-2}$ & 3.7 & $160 y$ \\
\hline
\end{tabular}

${ }^{\text {a }} \mathrm{ATS}^{-2}$ is the average number of transformed sectors per $\mathrm{cm}^{2}$ of inoculated stem tissue 
Table 3 Average number of transformation events per $\mathrm{cm}^{-2}$ of tissue $\left(\mathrm{ATS}^{-2}\right)$ observed for the different promoter constructs

\begin{tabular}{ccc}
\hline Promoter & Populus $^{a}$ & Eucalyptus $^{a}$ \\
\hline EgCESA1 & $0.5(0.07)$ & $0.7(0.13)$ \\
EgCESA2 & $0.3(0.17)$ & $0.6(0.12)$ \\
EgCESA3 & $1.6(0.28)$ & $2.0(0.45)$ \\
EgCESA4 & $0.6(0.17)$ & $8.1(1.26)$ \\
EgCESA5 & $1.3(0.28)$ & $2.7(0.82)$ \\
EgCESA7 & $3.0(0.45)$ & $5.3(1.01)$ \\
AtCESA8 & $5.2(0.75)$ & $9.4(1.58)$ \\
$35 S F$ & $19.1(0.85)$ & $27.1(2.20)$ \\
$35 S G$ & $12.0(0.98)$ & $17.8(2.10)$ \\
\hline
\end{tabular}

${ }^{a} \mathrm{ATS}^{-2}$ values for each promoter in Eucalyptus and Populus with the standard error in brackets 
Table 4 Comparison of $\beta$-glucuronidase (GUS) expression frequencies observed for the CesA promoter constructs and for the CAMV35S promoter constructs in Eucalyptus and Populus stem tissues. Values below the diagonal are pair-wise comparisons within Eucalyptus and above the diagonal are within Populus

\begin{tabular}{|c|c|c|c|c|c|c|c|c|}
\hline \multirow[t]{2}{*}{ Chi-square values } & \multicolumn{8}{|c|}{ Populus } \\
\hline & EgCesA1 & EgCesA2 & EgCesA3 & EgCesA4 & EgCesA5 & EgCesA7 & AtCesA8 & $35 S A^{d}$ \\
\hline \multicolumn{9}{|l|}{ Eucalyptus } \\
\hline EgCesA1 & & $0.295^{c}$ & $1.373^{c}$ & $6.169^{b}$ & $6.46^{b}$ & $6.986^{b}$ & $3.863^{\mathrm{a}}$ & $13.754^{b}$ \\
\hline EgCesA2 & $0.708^{c}$ & & $1.112^{c}$ & $4.79^{\mathrm{a}}$ & $4.518^{a}$ & $5.317^{a}$ & $2.855^{c}$ & $9.186^{b}$ \\
\hline EgCesA3 & $2.839^{c}$ & $1.11^{c}$ & & $2.223^{c}$ & $2.449^{c}$ & $2.941^{c}$ & $1.003^{c}$ & $7.555^{b}$ \\
\hline EgCesA4 & $8.856^{b}$ & $11.05^{b}$ & $15.151^{b}$ & & $0.676^{c}$ & $0.661^{c}$ & $1.463^{c}$ & $1.869^{c}$ \\
\hline EgCesA5 & $9.976^{b}$ & $12.008^{b}$ & $16.123^{b}$ & $4.852^{c}$ & & $0.015^{c}$ & $1.047^{c}$ & $1.591^{c}$ \\
\hline EgCesA7 & $9.18^{b}$ & $11.363^{b}$ & $15.488^{b}$ & $0.108^{c}$ & $3.275^{c}$ & & $1.871^{c}$ & $3.952^{a}$ \\
\hline AtCesA8 & $0.024^{c}$ & $1.122^{c}$ & $3.258^{c}$ & $27.224^{b}$ & $27.855^{b}$ & $27.32^{b}$ & & $14.897^{b}$ \\
\hline 35SA & $29.165^{b}$ & $30.234^{b}$ & $37.791^{b}$ & $46.858^{b}$ & $11.278^{b}$ & $36.082^{b}$ & $103.367^{b}$ & \\
\hline
\end{tabular}

${ }^{a}$ Significance determination: >3.84 shows significant difference with one degree of freedom (dark grey shading)

b Significance determination: >5.99 shows significant difference with two degrees of freedom (light grey shading)

${ }^{\mathrm{c}}$ White cells indicate promoter comparisons where there was no significant difference in expression patterns

${ }^{\mathrm{d}}$ Only one of the two 35S promoter data sets were used as there was no significant difference between the two datasets

${ }^{\text {e }}$ Chi-squared values determined by pair-wise comparison of the frequency of GUS expression for different promoter constructs across the different stem tissues (P: phloem, X1: immature xylem and X2: mature xylem) with null hypothesis of equal expected frequency ratios for each comparison 
Table 5 The inter-specific comparison of $\beta$-glucuronidase (GUS) expression patterns observed in Populus and Eucalyptus cambial tissues for the EgCesA and CAMV35S promoters

\begin{tabular}{|c|ccccccccc|}
\hline Chi-squared value $^{\mathrm{e}}$ & \multicolumn{8}{|c|}{ Populus } \\
& EgCesA1 & EgCesA2 & EgCesA3 & EgCesA4 & EgCesA5 & EgCesA7 & AtCesA8 $^{3}$ & 35SA \\
\hline Eucalyptus & & & & & & & \\
EgCesA1 & $8.584^{\mathrm{b}}$ & $4.613^{\mathrm{a}}$ & $9.488^{\mathrm{b}}$ & $14.438^{\mathrm{b}}$ & $15.776^{\mathrm{b}}$ & $20.837^{\mathrm{b}}$ & $16.503^{\mathrm{b}}$ & $32.828^{\mathrm{b}}$ \\
EgCesA2 & - & $7.125^{\mathrm{b}}$ & $11.841^{\mathrm{b}}$ & $17.072^{\mathrm{b}}$ & $17.69^{\mathrm{b}}$ & $22.588^{\mathrm{b}}$ & $18.394^{\mathrm{b}}$ & $33.858^{\mathrm{b}}$ \\
EgCesA3 & - & - & $16.049^{\mathrm{b}}$ & $22.917^{\mathrm{b}}$ & $22.418^{\mathrm{b}}$ & $27.903^{\mathrm{b}}$ & $23.5^{\mathrm{b}}$ & $41.617^{\mathrm{b}}$ \\
EgCesA4 & - & - & - & $5.462^{\mathrm{a}}$ & $11.024^{\mathrm{b}}$ & $16.697^{\mathrm{b}}$ & $9.004^{\mathrm{b}}$ & $49.714^{\mathrm{b}}$ \\
EgCesA5 & - & - & - & - & $2.437^{\mathrm{c}}$ & $4.369^{\mathrm{a}}$ & $1.476^{\mathrm{c}}$ & $13.97^{\mathrm{b}}$ \\
EgCesA7 & - & - & - & - & - & $12.978^{\mathrm{b}}$ & $6.421^{\mathrm{b}}$ & $39.142^{\mathrm{b}}$ \\
AtCesA8 & - & - & - & - & - & - & $47.554^{\mathrm{b}}$ & $101.493^{\mathrm{b}}$ \\
CAMV35SA & - & - & - & - & - & - & - & $1.568^{\mathrm{c}}$ \\
\hline
\end{tabular}

${ }^{a}$ Significance determination: >3.84 shows significant difference with one degree of freedom (dark grey shading)

b Significance determination: >5.99 shows significant difference with two degrees of freedom (light grey shading)

${ }^{c}$ White cells indicate promoter comparisons where there was no significant difference in expression patterns

${ }^{\mathrm{d}}$ Only one of the two $35 \mathrm{~S}$ promoter data sets were used as there was no significant difference observed between the two datasets

${ }^{\text {e }}$ Chi-squared values determined by comparison of the frequency of GUS expression for different promoter constructs across the different stem tissues (P: phloem, X1: immature xylem and X2: mature xylem) of Populus and Eucalyptus plants with null hypothesis of equal expected frequency ratios for Populus and Eucalyptus tissues 
Figure legends

Fig.1 Representative somatic sectors (expected and observed) for different promoter types in woody stem tissues. a Schematic representation of the different somatic sectors that are typically observed in cross sections of transformed woody stem tissue during induced somatic sector analysis (ISSA) with constitutive CAMV35S driven GUS expression. Only tylose sectors are observed in the pre-existing xylem at the centre of the stem. All other sector types are observed in the wound site and across the newly formed cambial zone. b Reclassification of the different sector types (staining patterns) that can be formed during ISSA in woody stem tissues depending on the type of cell transformed (cambial initial, phloem mother cell or xylem mother cell) and the cell or tissue specificity of the promoter used to drive GUS expression. Sector types were classified depending on the presence of GUS in the phloem (P), immature xylem (X1) mature xylem (X2) or a combination of these. The only sector types observed during this study were $\mathrm{X} 2+\mathrm{X} 1+\mathrm{P}, \mathrm{X} 1+\mathrm{X} 2, \mathrm{X} 1+\mathrm{P}, \mathrm{X} 1$ only and $\mathrm{P}$ only. c Cross section of a Populus stem showing a transformed cambial sector with GUS expression in the phloem (P), immature xylem (X1) and the mature xylem (X2) driven by the CAMV35S promoter, indicating that a cambial initial was transformed which continued to divide and produce xylem and phloem cells

Fig.2 The overall observed frequency of somatic sector types and cambial sector types observed in Populus and Eucalyptus stem tissues. The frequency of the different sector types for each promoter in Populus (a and c) and Eucalyptus (b and d) plants is indicated on the yaxis, while the promoters used for each transformation are indicated on the x-axis. The number next to each promoter name $(n)$ indicates the total number of sectors observed for that promoter. Of all sector types (a and b) counted, cambial sectors were found to be most highly abundant in Populus and Eucalyptus stems. The cambial sectors (c and d) were further classified into different subtypes (Fig. 1c) depending on GUS staining patterns in phloem (P), immature xylem $(\mathrm{X} 1)$ and mature xylem (X2) regions: $\mathrm{P}+\mathrm{X} 1+\mathrm{X} 2, \mathrm{X} 1+\mathrm{X} 2, \mathrm{P}+\mathrm{X} 1, \mathrm{X} 1$ only and P only

Fig.3 Spatiotemporal frequencies of cambial staining patterns observed for the different promoter constructs in the woody stem tissues of Populus (a) and Eucalyptus (b) plants. The sector frequency of GUS expression in the cambially derived stem tissues (phloem P-green, immature xylem X1-red and mature xylem X2-blue) is indicated on the y-axis and the promoter constructs are listed on the x-axis. The $n$ indicates the number of sectors counted for each promoter

Fig.4 Examples of cambial staining patterns observed in Eucalyptus and Populus stems. EgCesA3 (a) and AtCesA8 (b) promoter constructs showing activity in the X1 region only (black arrows) in Eucalyptus stems, whereas the same promoters (e and f, respectively) showed activity in the $\mathrm{X} 1$ and $\mathrm{P}$ regions in Populus stems. The EgCesA5 promoter construct showing activity in the $\mathrm{X} 1$ and $\mathrm{P}$ regions in Eucalyptus (c) and Populus (g) stems. $35 \mathrm{~S}$ promoter activity was often seen in all three regions (X2, X1 and P) in Eucalyptus (d) and Populus $(\mathbf{h})$ stems. $\mathrm{nfx}=$ newly formed $\mathrm{xylem}, \mathrm{vc}=$ vascular cambium and $\mathrm{ws}=$ wound site 

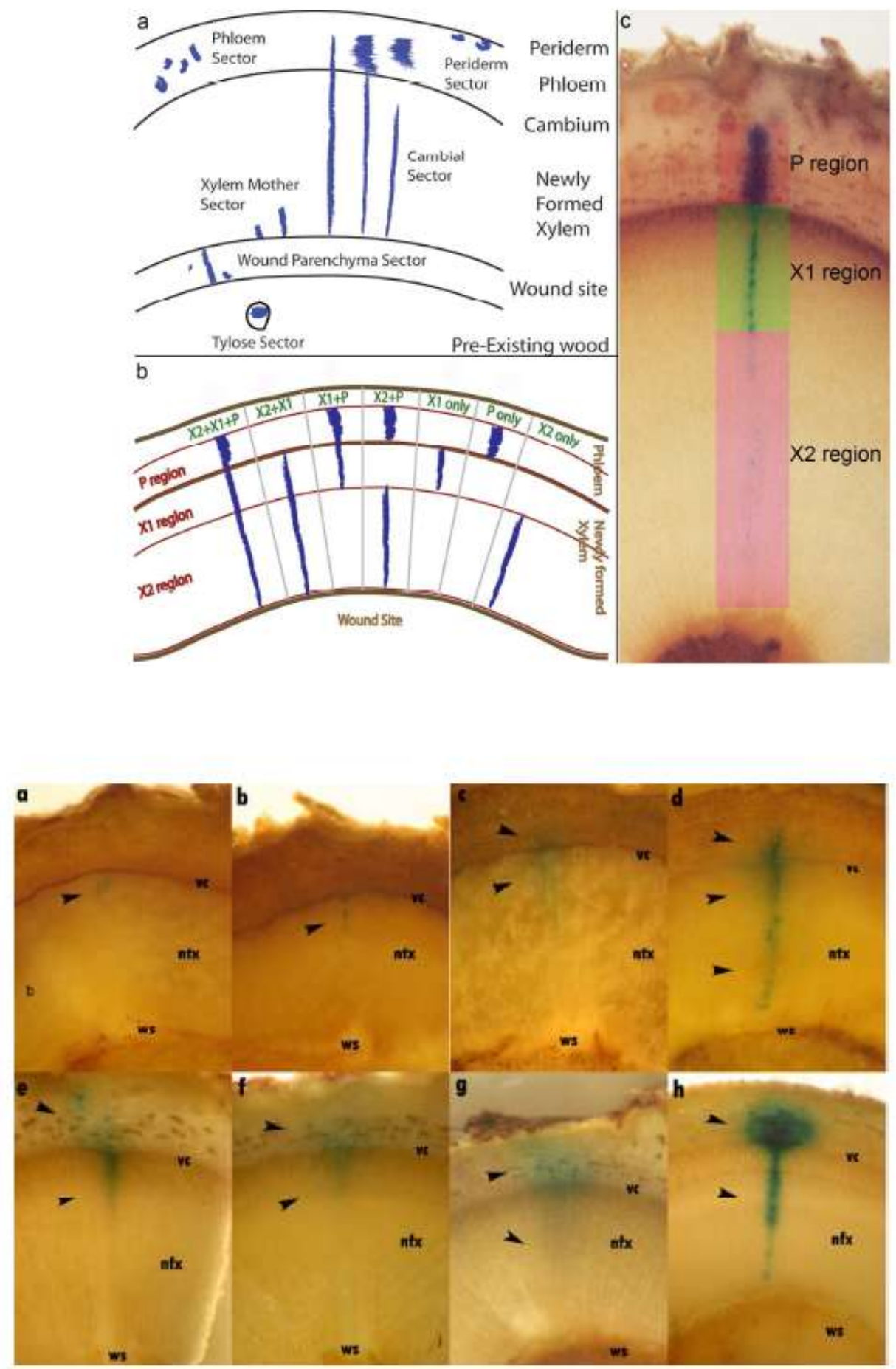

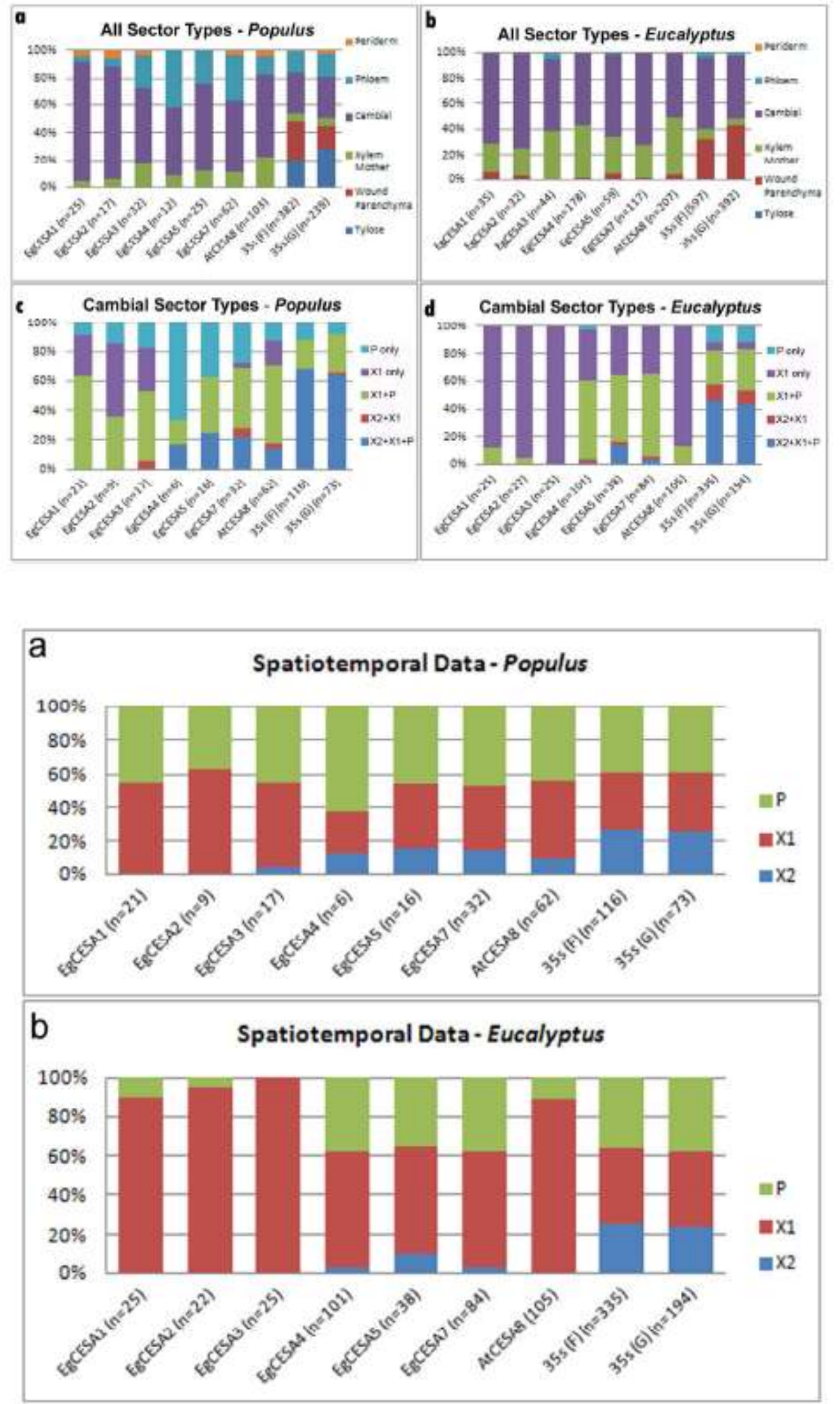

\section{References}


Alwen A, Moreno RMB, Vincente O, Heberle-Bors E (1992) Plant endogenous $\beta$ glucuronidase activity: how to avoid interference with the use of the E. coli $\beta$-glucuronidase as a reporter gene in transgenic plants. Transgenic Res 1: 63-70

Arioli T, Peng L, Betzner AS, Burn J, Wittke W, Herth W, Camilleri C, Hofte H, Plazinski J, Birch R, Cork A, Glover J, Redmond J, Williamson RE (1998) Molecular analysis of cellulose biosynthesis in Arabidopsis. Science 279: 717-720

Beeckman T, Przemeck Gerhard KH, Stamatiou G, Lau R, Terryn N, De Rycke R, Inze D, Berleth T (2002) Genetic complexity of CESA gene function in Arabidopsis embryogenesis. Plant Physiol 130: 1883-1893

Benfey PN, Chua N-H (1990) The cauliflower mosaic virus 35S promoter: combinatorial regulation of transcription in plants. Science 250: 959-966

Carroll A, Specht CD (2011) Understanding plant cellulose synthases through a comprehensive investigation of the cellulose synthase family sequences. Front Plant Sci 2:5

Creux NM, Ranik M, Berger DK, Myburg AA (2008) Comparative analysis of orthologous cellulose synthase promoters from Arabidopsis, Populus and Eucalyptus: evidence of conserved regulatory elements in angiosperms. New Phytol 179: 722-737

Curtis MD, Grossniklaus U (2003) A gateway cloning vector set for high-throughput functional analysis of genes in planta. Plant Physiol 133: 462-469

Desprez T, Vernhettes S, Fagard M, Refrégier G, Desnos T, Aletti E, Py N, Pelletier S, Höfte H (2002) Resistance against herbicide isoxaben and cellulose deficiency caused by distinct mutations in same cellulose synthase isoform CESA6. Plant Physiol 128: 482-490

Djerbi S, Lindskog M, Arvestad L, Sterky F, Teeri TT (2005) The genome sequence of black cottonwood (Populus trichocarpa) reveals 18 conserved cellulose synthase (CesA) genes. Planta 221: 739-746

Dowell RD (2010) Transcription factor binding variation in the evolution of gene regulation. Trends Genet 26: 468-475

Fei H, Chaillou S, Hirel B, Polowick P, Mahon JD, Vessey JK (2006) Effects of the overexpression of a soybean cytosolic glutamine synthetase gene (GS15) linked to organ-specific promoters on growth and nitrogen accumulation of pea plants supplied with ammonium. Plant Physiol Biochem 44: 543-550

Grattapaglia D, Plomion C, Kirst M, Sederoff RR (2009) Genomics of growth traits in forest trees. Curr Opin Plant Biol 12: 148-156

Hamann T, Osborne E, Youngs HL, Misson J, Nussaume L, Somerville C (2004) Global expression analysis of CESA and CSL genes in Arabidopsis. Cellulose 11: 279-286

Hinchee M, Rottmann W, Mullinax L, Zhang C, Chang S, Cunningham M, Pearson L, Nehra N, Tomes D, Lakshmanan P, Songstad D (2011) Short-rotation woody crops for bioenergy and biofuels applications. In: Dwight T, Lakshmanan P, songstad D (eds) Biofuels. Global impact on renewable energy, production agriculture, and technological advancements. Springer, New York, pp 139-156

Ho MCW, Johnsen H, Goetz SE, Schiller BJ, Bae E, Tran DA, Shur AS, Allen JM, Rau C, Bender W, Fisher WW, Celniker SE, Drewell RA (2009) Functional evolution of cisregulatory modules at a homeotic gene in Drosophila. PLoS Genet 5: e1000709

Hu R, Qi G, Kong Y, Kong D, Gao Q, Zhou G (2010) Comprehensive analysis of NAC domain transcription factor gene family in Populus trichocarpa. BMC Plant Biol 10: 145 
Hussey S, Mizrachi E, Spokevicius A, Bossinger G, Berger D, Myburg A (2011) SND2, a NAC transcription factor gene, regulates genes involved in secondary cell wall development in Arabidopsis fibres and increases fibre cell area in Eucalyptus. BMC Plant Biol 11: 173

Jefferson RA, Kavanagh TA, Bevan MW (1987) GUS fusions: beta-glucuronidase as a sensitive and versatile gene fusion marker in higher plants. EMBO J 6: 3901-3907

Kimura S, Laosinchai W, Itoh T, Cui X, Linder CR, Brown RM, Jr. (1999) Immunogold labeling of rosette terminal cellulose-synthesizing complexes in the vascular plant Vigna angularis. Plant Cell 11: 2075-2086

Ko J-H, Kim H-T, Hwang I, Han K-H (2012) Tissue-type-specific transcriptome analysis identifies developing xylem-specific promoters in poplar. Plant Biotechnol 10: 587-596

Kumar M, Thammannagowda S, Bulone V, Chiang V, Han K-H, Joshi CP, Mansfield SD, Mellerowicz E, Sundberg B, Teeri T, Ellis BE (2009) An update on the nomenclature for the cellulose synthase genes in Populus. Trends Plant Sci 14: 248-254

Lazo G, Stein P, Ludwig R (1991) A DNA transformation-competent Arabidopsis genomic library in Agrobacterium. Biotechnology 9: 963-967

Mansfield SD (2009) Solutions for dissolution-engineering cell walls for deconstruction. Curr Opin Biotech 20: 286-294

Mizrachi E, Mansfield SD, Myburg AA (2012) Cellulose factories: advancing bioenergy production from forest trees. New Phytol 194: 54-62

Mu XJ, Lu ZJ, Kong Y, Lam HYK, Gerstein MB (2011) Analysis of genomic variation in non-coding elements using population-scale sequencing data from the 1000 Genomes Project. Nucleic Acids Res 39: 7058-7076

Odell JT, Nagy F, Chua N-H (1985) Identification of DNA sequences required for activity of the cauliflower mosaic virus $35 \mathrm{~S}$ promoter. Nature 313: 810-812

Plomion C, Leprovost G, Stokes A (2001) Wood formation in trees. Plant Physiol 127: 15131523

Popper ZA, Michel G, Herve C, Domozych DS, Willats WGT, Tuohy MG, Kloareg B, Stengel DB (2011) Evolution and diversity of plant cell walls: from algae to flowering plants. Annu Rev Plant Biol 62: 567-590

Qin JY, Zhang L, Clift KL, Hulur I, Xiang AP, Ren B-Z, Lahn BT (2010) Systematic comparison of constitutive promoters and the doxycycline-inducible promoter. PLoS One 5: e10611

Ranik M, Myburg AA (2006) Six new cellulose synthase genes from Eucalyptus are associated with primary and secondary cell wall biosynthesis. Tree Physiol 26: 545-556

Rathmann R, Szklo A, Schaeffer R (2010) Land use competition for production of food and liquid biofuels: An analysis of the arguments in the current debate. Renew Energ 35: 14-22

Richmond TA, Somerville CR (2000) The cellulose synthase superfamily. Plant Physiol 124: 495-498

Sambrook J, Russell DW (2001) Molecular cloning: A laboratory manual. Cold Spring Harbour Press, New York

Samuga A, Joshi CP (2004) Differential expression patterns of two new primary cell wallrelated cellulose synthase cDNAs, PtrCesA6 and PtrCesA7 from aspen trees. Gene 334: 7382 
Scheible WR, Eshed R, Richmond T, Delmer D, Somerville C (2001) Modifications of cellulose synthase confer resistance to isoxaben and thiazolidinone herbicides in Arabidopsis ixr1 mutants. Proc Natl Acad Sci USA 98: 10079-10084

Seguin A (2011) How could forest trees play an important role as feedstock for bioenergy production? Curr Opin Environ Sustain 3: 90-94

Song D, Shen J, Li L (2010) Characterization of cellulose synthase complexes in Populus xylem differentiation. New Phytol 187: 777-790

Spokevicius AV, Southerton SG, MacMillan CP, Qiu D, Gan S, Tibbits JFG, Moran GF, Bossinger $G$ (2007) $\beta$-Tubulin affects cellulose microfibril orientation in plant secondary fibre cell walls. Plant J 51: 717-726

Spokevicius AV, Van Beveren K, Leitch MM, Bossinger G (2005) Agrobacterium-mediated in vitro transformation of wood-producing stem segments in eucalypts. Plant Cell Rep 23: 617-624

Stork J, Harris D, Griffiths J, Williams B, Beisson F, Li-Beisson Y, Mendu V, Haughn G, DeBolt S (2010) CELLULOSE SYNTHASE9 serves a nonredundant role in secondary cell wall synthesis in Arabidopsis epidermal testa cells. Plant Physiol 153: 580-589

Suzuki S, Li LG, Sun YH, Chiang VL (2006) The cellulose synthase gene superfamily and biochemical functions of xylem-specific cellulose synthase-like genes in Populus trichocarpa. Plant Physiol 142: 1233-1245

Taylor NG (2008) Cellulose biosynthesis and deposition in higher plants. New Phytol 178: 239-252

Taylor NG, Howells RM, Huttly AK, Vickers K, Turner SR (2003) Interactions among three distinct CESA proteins essential for cellulose synthesis. Proc Natl Acad Sci USA 100: 14501455

Taylor NG, Laurie S, Turner SR (2000) Multiple cellulose synthase catalytic subunits are required for cellulose synthesis in Arabidopsis. Plant Cell 12: 2529-2539

Turner SR, Somerville CR (1997) Collapsed xylem phenotype of Arabidopsis identifies mutants deficient in cellulose deposition in the secondary cell wall. Plant Cell 9: 689-701

Tuskan GA, DiFazio S, Jansson S et al. (2006) The genome of black cottonwood, Populus trichocarpa (Torr. \& Gray). Science 313: 1596-1604

Van Beveren K, Spokevicius AV, Tibbits J, Wang Q, Bossinger G (2006) Transformation of cambial tissue in vivo provides efficient means for Induced Somatic Sector Analysis (ISSA) and gene testing in stems of woody plants species. Funct Plant Biol 33: 629-638

Yin Y, Huang J, Xu Y (2009) The cellulose synthase superfamily in fully sequenced plants and algae. BMC Plant Biol 9: 99

Zhang P, Bohl-Zenger S, Puonti-Kaerlas J, Potrykus I, Gruissem W (2003) Two cassava promoters related to vascular expression and storage root formation. Planta 218: 192-203

Zhong R, Lee C, Ye Z-H (2010) Evolutionary conservation of the transcriptional network regulating secondary cell wall biosynthesis. Trends Plant Sci 15: 625-632 


\section{University Library}

\section{- M M N E R VA A gateway to Melbourne's research publications}

Minerva Access is the Institutional Repository of The University of Melbourne

Author/s:

Creux, NM;Bossinger, G;Myburg, AA;Spokevicius, AV

Title:

Induced somatic sector analysis of cellulose synthase (CesA) promoter regions in woody stem tissues

Date:

2013-03-01

\section{Citation:}

Creux, N. M., Bossinger, G., Myburg, A. A. \& Spokevicius, A. V. (2013). Induced somatic sector analysis of cellulose synthase (CesA) promoter regions in woody stem tissues. PLANTA, 237 (3), pp.799-812. https://doi.org/10.1007/s00425-012-1792-x.

Persistent Link:

http://hdl.handle.net/11343/282969 